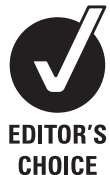

Oral Medicine Department, Eastman Dental Hospital, London, UK

\section{Correspondence to} Professor Joanna M Zakrzewska, Oral Medicine Department, Eastman Dental Hospital, 256 Gray's Inn Road, London WC1X 8LD, UK: jzakrzewska@nhs.net

Received 7 May 2009 Accepted 30 December 2010 Published Online First 14 April 2011

\title{
Trigeminal neuralgia: the diagnosis and management of this excruciating and poorly understood facial pain
}

\author{
Joanna M Zakrzewska, Roddy McMillan
}

\begin{abstract}
Trigeminal neuralgia is defined as sudden, usually unilateral, severe, brief, stabbing recurrent episodes of pain within the distribution of one or more branches of the trigeminal nerve, which has a profound effect on quality of life. The diagnosis is made on history alone, and time needs to be taken to elicit the key features and differentiate from toothache or one of the trigeminal autonomic cephalalgias. Most trigeminal neuralgia is idiopathic, but a small percentage is due to secondary causes-for example, tumours or multiple sclerosis - which can be picked up on CT or MRI. Recently published international guidelines suggest that carbamazepine and oxcarbazepine are the first-line drugs. There is limited evidence for the use of lamotrigine and baclofen. If there is a decrease in efficacy or tolerability of medication, surgery needs to be considered. A neurosurgical opinion should be sought early. There are several ablative, destructive procedures that can be carried out either at the level of the Gasserian ganglion or in the posterior fossa. The only non-destructive procedure is microvascular decompression (MVD). The ablative procedures give a $50 \%$ chance of patients being pain free for 4 years, compared with $70 \%$ of patients at 10 years after MVD. Ablative procedures result in sensory loss, and MVD carries a $0.2-0.4 \%$ risk of mortality with a $2-4 \%$ chance of ipsilateral hearing loss. Surgical procedures result in markedly improved quality of life. Patient support groups provide information and support to those in pain and play a crucial role.
\end{abstract}

\section{INTRODUCTION}

The International Association for the Study of Pain defines trigeminal neuralgia (TN) as 'sudden, usually unilateral, severe, brief, stabbing, recurrent episodes of pain in the distribution of one or more branches of the trigeminal nerve. ${ }^{1}$ Until fairly recently, the only high-quality epidemiology study on TN was from the USA, which showed an annual incidence of 4-5 per $100000 .^{2}$ However, recent surveys from both the $\mathrm{UK}^{3}$ and the Netherlands ${ }^{4}$ show much higher incidences of 26.8 and 28.9 per 100000 , respectively.

A recent European study using a sample of 602 patients with neuropathic pain found that $14 \%$ had TN. ${ }^{5}$ This group of 82 patients with TN were found to have moderately severe pain and poor quality of life despite $94 \%$ of them taking medication. We suggest that this is in part due to suboptimal management strategies secondary to lack of knowledge about this relatively rare disease. ${ }^{6}$ Both dental and medical professionals often misdiagnose the disorder, potentially resulting in unnecessary dental extractions or inappropriate prescription of drugs such as opioids.

The UK survey ${ }^{3}$ shows a higher incidence in females in all age groups, and a peak incidence between 45 and 59 years, which is lower than previous epidemiological data. However, it is likely that some of these cases have been potentially misdiagnosed as dental pain, sinusitis or even temporomandibular disorders, as these can present with similar symptoms to TN. ${ }^{7}$ Koopman et a ${ }^{8}$ have shown that misdiagnosis by general practitioners can be as high as $48 \%$. As conducted by previous authors, they identified cases from general practice records, but experienced neurologists then carried out interviews in the suspected cases and revised the diagnoses. We believe that the apparent rise in the reported incidence of $\mathrm{TN}$ is probably secondary to misreporting and misdiagnosis rather than any other significant causes.

TN is divided into what is termed by The International Headache Society as 'classical' and 'symptomatic' (secondary). ${ }^{9}$ Those with symptomatic TN have either a compression of the trigeminal nerve caused by tumours (benign and malignant) or other structural abnormalities such as arteriovenous malformations, or have multiple sclerosis (MS). Classical TN includes all cases with no definitive aetiology identified apart from a vascular compression of the trigeminal nerve. Not every patient with TN fulfils all of the diagnostic criteria identified by the International Headache Society (table 1), and the terms atypical TN or type II TN are used to describe these patients. ${ }^{10} 11$

The aims of this review are to describe the nature of TN and outline the current approaches to the diagnosis and management of this debilitating facial pain condition. Owing to a dearth of robust evidence relating to certain aspects of TN management, we have supplemented the discussion with personal commentary.

\section{CLINICAL FEATURES}

The basic clinical features are shown in table 1 . The diagnostic criteria have not been validated by case-control studies or according to evidence-based methodologies, in part because there are no objective tests. ${ }^{10}$

It is essential to listen to the description that the patient provides, as often they will use words that are pathognomonic for TN. Below are a few descriptions taken from patient narratives ${ }^{12}$ :

- 'Ice pick, shocks, live 300-volt current, electric shock-like pains'

- 'Constant hot knife jabbing volts or stabs in my right cheek area'

- 'Sharp electric-like quality' 
Table 1 Diagnostic criteria of trigeminal neuralgia (TN) and how these compare with other differential diagnoses

\begin{tabular}{|c|c|c|c|c|c|c|}
\hline Symptom & TN & Pulpitis & TMD & Neuropathic trigeminal pain & SUNA/SUNCT & Paroxysmal hemicrania \\
\hline Character & $\begin{array}{l}\text { Shooting, stabbing, sharp, } \\
\text { electric }\end{array}$ & $\begin{array}{l}\text { Sharp, aching, } \\
\text { throbbing }\end{array}$ & $\begin{array}{l}\text { Dull, aching, nagging, } \\
\text { sharp at times }\end{array}$ & Aching, throbbing & Burning, stabbing, sharp & $\begin{array}{l}\text { Throbbing, boring, } \\
\text { stabbing }\end{array}$ \\
\hline $\begin{array}{l}\text { Site/ } \\
\text { radiation }\end{array}$ & $\begin{array}{l}\text { Trigeminal distribution only, } \\
\text { intraoral and extraoral, } \\
\text { affects V(a) rarely }\end{array}$ & $\begin{array}{l}\text { Around a tooth, } \\
\text { intraoral }\end{array}$ & $\begin{array}{l}\text { Preauricular, radiates down } \\
\text { mandible, temple area, } \\
\text { may be postauricular or } \\
\text { neck }\end{array}$ & $\begin{array}{l}\text { Around tooth or area of } \\
\text { past trauma/dental surgery } \\
\text { or facial trauma }\end{array}$ & $\begin{array}{l}\text { Periorbital but can affect } \\
\text { maxillary division }\end{array}$ & Orbit, temple \\
\hline Severity & Moderate to severe & Mild to moderate & Mild to severe & Moderate & Severe & Severe \\
\hline Duration & $1-60 \mathrm{~s}$ Refractory period & $\begin{array}{l}\text { Rapid but no } \\
\text { refractory period }\end{array}$ & $\begin{array}{l}\text { Not refractory, lasts for } \\
\text { hours, mainly continuous } \\
\text { can be episodic }\end{array}$ & $\begin{array}{l}\text { Continuous soon after } \\
\text { injury }\end{array}$ & Episodic $5-240 \mathrm{~s}$ & Episodic $2-30 \mathrm{~min}$ \\
\hline Periodicity & $\begin{array}{l}\text { Rapid onset and } \\
\text { termination, complete } \\
\text { periods of remission weeks } \\
\text { to months }\end{array}$ & $\begin{array}{l}\text { Unlikely to be more } \\
\text { than } 6 \text { months }\end{array}$ & $\begin{array}{l}\text { Tends to build up slowly } \\
\text { and diminish slowly, lasts } \\
\text { for years }\end{array}$ & Continuous & $\begin{array}{l}\text { Numerous, can be periods } \\
\text { of complete remission }\end{array}$ & $\begin{array}{l}1-40 \text { a day, can be } \\
\text { periods of complete } \\
\text { remission }\end{array}$ \\
\hline $\begin{array}{l}\text { Provoking } \\
\text { factors }\end{array}$ & $\begin{array}{l}\text { Light touch, } \\
\text { non-nociceptive }\end{array}$ & $\begin{array}{l}\text { Hot/cold applied to } \\
\text { teeth }\end{array}$ & $\begin{array}{l}\text { Clenching teeth, prolonged } \\
\text { chewing, yawning }\end{array}$ & Light touch & Light touch & Nil \\
\hline
\end{tabular}

SUNA, short unilateral neuralgiform pain with autonomic symptoms; SUNCT, short unilateral neuralgiform pain with conjunctival tearing; TMD, temporomandibular disorder.

- 'Shooting jolts of electricity directly into the raw nerves'

- 'While brushing my teeth one morning I got a bolt of lightning exploded in my face.'

- 'The pain was sharp stabbing, electrical shock-like pains that would last for only seconds; however, there would be a dull sensation after the pain subsided.'

- 'It is like you have a live wire, and you take the sheeting off the wire and sparks are flying off that.'

These descriptors imply not only the sharpness of the pain but also its rapidity and severity. Many patients vividly remember their first attack, and surgeons have gone so far as to say that patients who have a memorable onset are more likely to have good outcomes. ${ }^{13}$ The pain develops rapidly and lasts for no more than 2 min. Sometimes it is difficult for patients to appreciate that there are very short breaks between each attack of pain. Characteristically there is a refractory period. The severity of the pain varies from mild to extremely severe, resulting in weight loss and inability to maintain good oral hygiene.

The pain is provoked by light touch, often by intraoral triggers, but it is essential to establish whether there are also extraoral triggers, as these then help to differentiate it from dental causes. Reported trigger factors are:

- washing the face

- brushing teeth

- shaving

- applying make up

- going out in cold wind

- vibrations from walking

An important distinguishing factor from the rarer trigeminal autonomic cephalalgias is that there are no autonomic symptoms. Those patients diagnosed as having atypical or type II TN tend to have a background, milder aching or burning type pain which can persist for over 30 min. ${ }^{11}{ }^{14}$ Pain located only in the first division of the trigeminal nerve needs to be more carefully evaluated, as it is more likely to be a trigeminal autonomic cephalalgia than $\mathrm{TN}$.

\section{IMPACT ON QUALITY OF LIFE}

$\mathrm{TN}$ is a debilitating pain condition which clearly disrupts the quality of life. However, very few studies have attempted to measure the impact of TN on quality of life. Two long-term cohort studies ( 3 and 13 years) have shown that many patients have depression, which can be reversed following surgery. ${ }^{15} 16$ Moreover, narratives obtained from patient focus groups and material submitted for the writing of TN literature support this finding and illustrate how the fear of pain recurrence affects daily living. ${ }^{12}$

The disruption to daily living caused by TN is illustrated by the following patient narratives:

- 'Isolation, depression, fear of increasing pain are just some of the emotions I try to work through.'

- 'TN does changes your identity. Suddenly you see how precious life can be and it makes you reflect on what you are doing.'

- 'It is so hard to show my pain. I don't want people to feel bad around me or feel sorry for me. I feel my pain makes them distant ... I try to appear cheerful when I am really sad inside... when my depression is up high I can't eat, sleep or think of anything positive.'

- 'I have decided not to pursue any more teaching responsibilities, although this is what I had hoped to do after I retire from my current position.'

- 'I spent my waking hours trying to overdose, screaming and crying for relief. Emotions? Suicidal at worst, depressed at best.'

Often patients will not voice these emotions, as they think that doctors only want the medical symptoms. However, if more doctors were to hear these stories, it would increase their empathy towards this poorly understood group of patients.

\section{DIFFERENTIAL DIAGNOSES}

There are a variety of differential diagnoses to be considered when dealing with a suspected case of TN. Several of the key differentials are summarised in table 1.

\section{PATHOGENESIS}

The ignition hypothesis as described by Devor et al is the most widely accepted hypothesis for the pathophysiology of TN. ${ }^{17}$ According to it, TN results from specific abnormalities of 
trigeminal afferent neurons in the trigeminal root or ganglion. Injury renders the axons hyperexcitable, resulting in paroxysmal pain discharges. Surgeons have shown that, at the entry point of the trigeminal nerve into the brain stem (root entry zone), there is in most cases a compression of the nerve, usually caused by vascular structures (figure 1). Electron microscopy studies on trigeminal nerves in this area have shown evidence of both demyelination and remyelination. ${ }^{18}$ These partially injured sensory neurons thus become hyperexcitable and exhibit a phenomenon known as 'after discharge'. These after discharge bursts may be triggered by an external stimulus and extend beyond the duration of the stimulus. They can then also recruit additional neighbouring neurons, leading to a rapid build up of electrical activity, which results in a paroxsymal explosion of pain. Ephaptic cross-talk-that is, electrical cross-talk among neurons-also takes place and leads to further amplification. This is possible because the insulation has been eroded and the fibres lie in close contact with each other. Characteristically, TN attacks are rapid, and Devor et al explain the stop mechanism as being due to post-burst hyperpolarisation, which is due to influx of potassium ions into the channels, making the nerve refractory to further excitation. ${ }^{17}$

\section{Investigations}

Patient history is the most useful tool for diagnosing classical $\mathrm{TN}$. However, recent advances in neuroimaging have improved the ability to diagnose symptomatic TN. MRIs are used to both identify these cases and determine whether there is a vascular compression of the trigeminal nerve. A major risk factor for $\mathrm{TN}$ has been shown to be $\mathrm{MS}^{2}$; although a relatively rare cause, it is crucial that it is identified, as management can vary from antiepileptic drugs to major surgery.

Recent guidelines issued by the American Academy of Neurology (AAN) and the European Federation of Neurological Societies (EFNS) have failed to find sufficient evidence to

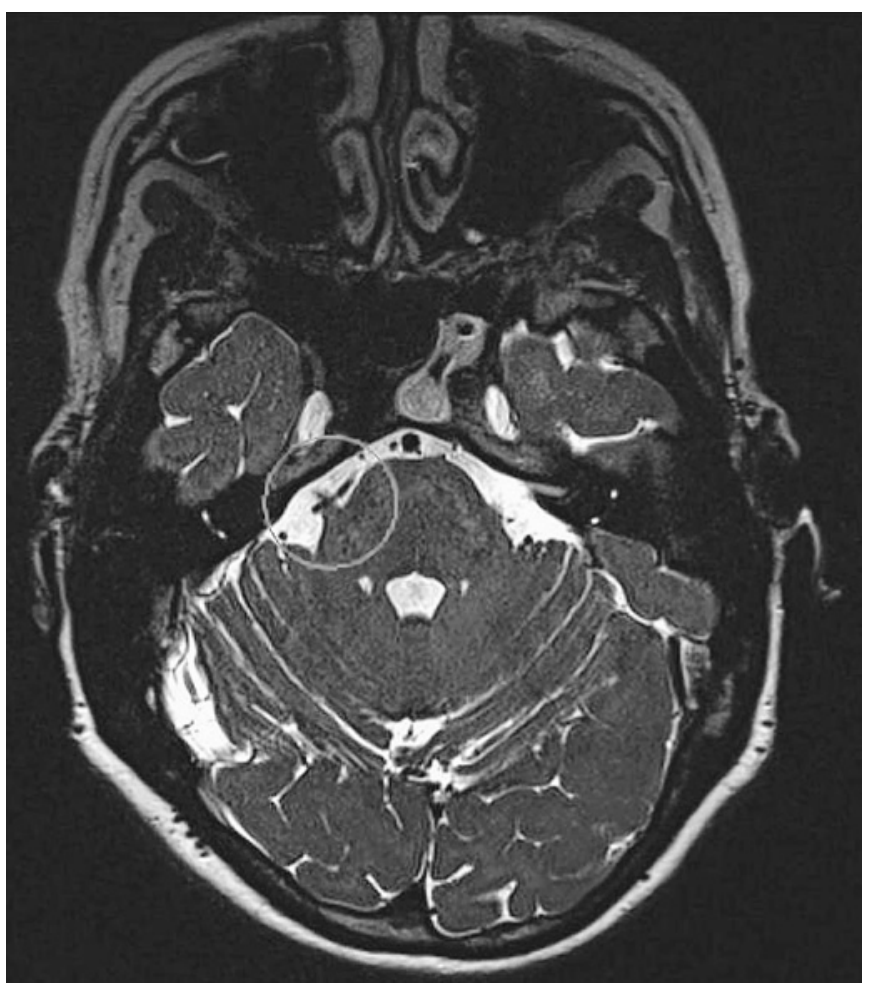

Figure $1 \mathrm{MRI}$ showing neurovascular compression of right trigeminal nerve. support or refute the fact that the presence of a neurocompression is the cause of TN. ${ }^{19}{ }^{20}$ Neuroimaging will identify the cause in patients with symptomatic $\mathrm{TN}$ - that is, MS plaques, compressions.

Neurophysiological tests may be helpful in distinguishing symptomatic from classical TN, as the former may have:

- abnormal trigeminal reflexes (specificity 94\%, sensitivity $87 \%)$

- abnormal trigeminal nerve-evoked potentials

- trigeminal sensory deficits and or bilateral involvement

However, involvement of first division of the trigeminal nerve and unresponsiveness to treatment are probably not associated with an increased risk of symptomatic TN. ${ }^{19} 20$

\section{MEDICAL MANAGEMENT}

There are now several systematic reviews, including Cochrane collaborations, detailing the use of drugs in $\mathrm{TN}$, in addition to guidelines for both general medical practitioners and specialists. $^{19-25}$ Unfortunately, there have been few high-quality randomised controlled trials (RCTs), and many were conducted using small cohorts in single centres. The major drugs are summarised in table 2 .

It is important to check all dosages and formulations in the BNF.

All drugs will result in neurological side effects such as drowsiness, ataxia and diplopia at higher doses.

Carbamazepine is the drug of choice, as shown in table 2. It is highly effective and, in newly diagnosed patients, is likely to provide complete pain relief within a few days. It needs to be started at a low dose and increased slowly in order to minimise side effects. However, this drug results in multiple adverse effects including drug interactions. Therefore, this has led to the search for other similarly effective drugs with potentially less problematic side-effect profiles. Recent guidelines have suggested that the second-line drug should be oxcarbazepine, which is in fact a prodrug of carbamazepine. ${ }^{19} 20$ This drug does not use the liver cytochrome system and therefore does not result in such widespread drug interactions and is generally better tolerated. It must, however, be remembered that, given the chemical similarity of these drugs, allergic cross-reactions between the two drugs can occur. The AAN/EFNS guidelines suggest that lamotrigine and baclofen are other second-line drugs that could be prescribed. ${ }^{1920}$ More recently, a RCT of gabapentin with regular ropivacaine injections into the trigger sites suggested that this combination was highly effective. However, the patients in this trial were newly diagnosed and may therefore have been likely to go into remission. ${ }^{26}$

Adequate evidence was not found for acute management of TN attacks, although there are some case reports of the use of intravenous fosphenytoin. ${ }^{19} 20$ Topical injections of lidocaine into trigger points as conducted in the field of dentistry will provide immediate but short-lasting pain relief. There are no RCTs on the use of oral or intravenous opioids in the treatment of TN. Pregabalin has been shown to be useful in a prospective open-label study, ${ }^{27}$ whereas levetiracetam, although well tolerated, is not effective for severe $\mathrm{TN}^{28}$

A considerable number of drugs are now available, especially anticonvulsants, which have been used in $\mathrm{TN}$, but the evidence for their efficacy is unproven by RCTs. There are no high-quality trials on which drug therapy can be based in MS patients with TN. ${ }^{19} 20$ This group of patients remain difficult to manage with pharmacotherapy, as often the side effects of the drugs compound the symptoms of the MS. 
Table 2 Major drugs used for medical management of trigeminal neuralgia

\begin{tabular}{|c|c|c|c|c|}
\hline Drug & Daily dose range & Side effects & Use & Comments \\
\hline \multicolumn{5}{|l|}{ Drugs used in RCTs } \\
\hline Carbamazepine (CBZ) & $300-1000 \mathrm{mg}$ & $\begin{array}{l}\text { Neurological, } \\
\text { dose-related }\end{array}$ & $\begin{array}{l}\text { Begin with small doses, } \\
\text { depending on tolerability, } \\
\text { retard version useful at night }\end{array}$ & $\begin{array}{l}\text { Beware drug interactions } \\
\text { (eg, warfarin-CBZ takes up to } 3 / 52 \text { to } \\
\text { have a full effect, so dosages } \\
\text { may need to be adjusted) }\end{array}$ \\
\hline Oxcarbazepine & $300-1200 \mathrm{mg}$ & $\begin{array}{l}\text { Neurological, } \\
\text { hyponatraemia } \\
\text { at higher doses }\end{array}$ & Use on a four times a day basis & Hyponatraemia at higher doses \\
\hline Baclofen & $50-80 \mathrm{mg}$ & Neurological & Begin very slowly, frequent dosage & $\begin{array}{l}\text { Withdraw drug slowly to avoid side } \\
\text { effects. Useful in patients with MS }\end{array}$ \\
\hline Lamotrigine & $200-400 \mathrm{mg}$ & Neurological & $\begin{array}{l}\text { Initially very slow escalation. Can } \\
\text { use in combination with CBZ }\end{array}$ & $\begin{array}{l}\text { Rashes common if increase dose } \\
\text { too quickly }\end{array}$ \\
\hline $\begin{array}{l}\text { Gabapentin with } \\
\text { ropivacaine }\end{array}$ & $\begin{array}{l}1800-3600 \\
\text { gabapentin mg } \\
\text { (RCT utilised up } \\
\text { to } 900 \mathrm{mg} \text { ) with } 4 \mathrm{mg} \\
\text { ropivicaine injected } \\
\text { into each trigger point }\end{array}$ & Neurological & $\begin{array}{l}\text { Ropivacaine injected weekly into } \\
\text { trigger areas }\end{array}$ & $\begin{array}{l}\text { Use of ropivacaine reduced dose of } \\
\text { gabapentin required. Very small trial } \\
\text { in newly diagnosed patients. }\end{array}$ \\
\hline \multicolumn{5}{|c|}{ Drugs not evaluated in RCTs } \\
\hline Phenytoin & $200-300 \mathrm{mg}$ & Neurological & Can use with carbamazepine & $>300 \mathrm{mg}$ can lead to severe side effects \\
\hline Sodium valproate & $600-1200 \mathrm{mg}$ & Neurological & Often used by neurologists & \\
\hline Pregabalin & $150-600 \mathrm{mg}$ & $\begin{array}{l}\text { Neurological, } \\
\text { dose-dependent, } \\
\text { higher doses cause } \\
\text { peripheral oedema }\end{array}$ & Effective used twice daily & Long-term cohort study shows promise \\
\hline
\end{tabular}

MS, multiple sclerosis; RCT, randomised controlled trial.

\section{PATIENT INFORMATION}

As well as knowing the optimal drugs to use, it is important that doctors understand how patients can maximise the effects of these drugs. We provide information leaflets, which include some of the following instructions:

- take a dose 30-45 min prior to activities that involve light touch

- space out the doses evenly throughout the day

- avoid rapid escalation; often one dose escalation every 3 days is sufficient

- take a larger dose at night especially if pain does not wake at night

- expect to get side effects; reduction of dose can sometimes help

- stop the drug if a rash develops

- return to the general practitioner for blood test monitoring, especially in the first few months of use

- inform any other prescribers that the patient is using these drugs, because possible drug interactions are common (eg, carbamazepine and warfarin)

- once all pain has stopped and it can no longer be triggered, consider slow reduction and eventual cessation of drug

- restart the drug if any pain returns

- keep pain diaries in order to aid accurate evaluation of drug efficacy.

\section{MANAGEMENT OF PHARMACORESISTANT PATIENTS}

Treatment may fail for a number of reasons, and this needs to be addressed before moving to the next stage. It is always worthwhile reconsidering the diagnosis if the drugs no longer provide adequate pain relief. There are few cohort data on the progression of TN. The single study that looked specifically at this issue suggests that patients are likely to have more frequent attacks with time. ${ }^{29}$ However, the rate of progression and rate of relapse remain unknown and currently no predictions can be provided. Two long-term drug studies suggest that drug therapy fails with time, not necessarily due to reduced serum drug levels. ${ }^{1630}$ Once medical management fails, either due to lack of pain control or poor tolerability of pharmacotherapy, then surgical treatments need to be considered.

The AAN/EFNS group searched for data to determine at what point surgical intervention should occur, and found that there was insufficient evidence to suggest when surgery should be offered. ${ }^{19} 20$ We believe it is important that patients discuss surgical options early in the disease process with a neurosurgeon. Once the pain becomes severe and patients are on high-dose medication, it is often difficult for them to provide wholly informed consent for any proposed surgical procedures. A recent study on how patients make decisions about treatment suggests that, in a hypothetical situation, patients would opt to have surgical treatment rather than medical management. ${ }^{31}$

\section{SURGICAL INTERVENTIONS}

There are a wide variety of surgical treatments available and only one of these, microvascular decompression, aims to preserve trigeminal nerve function intact. All of the other procedures can be termed destructive or ablative, as they aim to reduce sensory input and hence give rise to a degree of nerve damage. The interventions are performed at three target areas:

- peripheral-that is, distal to the Gasserian ganglion at specified trigger points

- Gasserian ganglion level

- posterior fossa at the root entry zone.

These techniques are summarised in table 3 . The data are based on the AAN/EFNS findings. ${ }^{19} 20$

\section{Peripheral techniques}

A wide variety of peripheral techniques have been described including: cryotherapy, neurectomies, peripheral acupuncture, peripheral radiofrequency thermocoagulations (RFTs) and a variety of injections, such as alcohol, phenol and streptomycin. Only the latter has been reported in two RCTs, which demonstrated that it was ineffective. ${ }^{32} 33$ All of the other studies were case series which failed to use independent observers to assess outcomes. There is therefore insufficient evidence to support the use of peripheral treatments. 
Table 3 Surgical treatments for trigeminal neuralgia

\begin{tabular}{|c|c|c|c|c|}
\hline Procedure & $\begin{array}{l}\text { Pain relief duration } \\
\text { (Kaplan-Meier) }\end{array}$ & Mortality & Morbidity & Comments \\
\hline $\begin{array}{l}\text { Peripheral techniques for } \\
\text { example cryosurgery, } \\
\text { neurectomy, laser, acupuncture, } \\
\text { thermocoagulation, injections of } \\
\text { streptomycin, alcohol, phenol }\end{array}$ & $50 \%$ for 10 months & Nil & $\begin{array}{l}\text { Local sensory loss, haematomas, } \\
\text { infections }\end{array}$ & $\begin{array}{l}\text { Can be performed quickly under local } \\
\text { anaesthetic. Suitable for medically unfit } \\
\text { for GA }\end{array}$ \\
\hline $\begin{array}{l}\text { Gasserian ganglion radiofrequency } \\
\text { thermocoagulation, glycerol, balloon } \\
\text { compression }\end{array}$ & $50 \%$ for 5 years & Very low & $\begin{array}{l}\text { Sensory loss, }>50 \% \text {; dysaesthesia, } \\
6 \% \text {; anaesthesia dolorosa, } 4 \% \text {; eye } \\
\text { complications, } 4 \% \text {; masticatory } \\
\text { complications, } 50 \%\end{array}$ & $\begin{array}{l}\text { Masticatory deficit mainly in balloon } \\
\text { compression. Shortest pain relief duration } \\
\text { after glycerol injection }\end{array}$ \\
\hline Gamma knife & $52 \%$ for 3 years & Nil & $\begin{array}{l}\text { Sensory loss, } 6-13 \% \text {; anaesthesia } \\
\text { dolorosa, very rarely }\end{array}$ & Pain relief can be delayed \\
\hline Microvascular decompression & $73 \%$ for 5 years & $0.2-0.5 \%$ & $\begin{array}{l}\text { Major postoperative morbidity, } 4 \% \text {; } \\
\text { ipsilateral hearing loss, } 10 \% \text {; transient } \\
\text { diplopia }\end{array}$ & Greatest improvement in quality of life \\
\hline
\end{tabular}

Percutaneous procedures at the level of the Gasserian ganglion All of these involve the insertion of a cannula through the foramen ovale into the trigeminal ganglion under heavy sedation or short general anaesthetic. The ganglion can then be lesioned using heat (RFT), injection of glycerol, or mechanical compression by the use of a balloon. Usually, an overnight inpatient stay is required for these procedures. There is limited evidence to support these treatments, with no RCTs and minimal evidence from prospective case series that have used independent outcome measures. The major outcome measure has been pain relief, and there are only a handful of studies that have measured quality of life. Up to $90 \%$ of patients are likely to obtain immediate pain relief, but this gradually reduces so that, by 5 years, $\sim 50 \%$ of patients will have a recurrence of pain. Mortality is understandably low with regard to these procedures. Given that all of these interventions are destructive, varying degrees of sensory loss are reported. This sensory loss can be very mild; however, up to $4 \%$ of patients may report severe anaesthesia dolorosa. When the treatments involve the first division of the trigeminal nerve, then eye problems such as corneal numbness and keratitis are possible. Pulsed RFT is a procedure whereby the RFT applied at the level of the Gasserian ganglion is a pulsed rather than continuous current. The perceived benefit of pulsed over continuous is the reduction in postoperative sensory loss. However, current evidence suggests the pain relief outcome of pulsed RFT is inferior compared with traditional RFT. ${ }^{34}$

\section{Gamma knife surgery}

This is an ablative procedure, which targets the trigeminal root entry zone in the posterior fossa and aims to focus a beam of radiation at this point. There have been trials to determine both the optimum dose of radiation and its precise location. Initial reports suggested that this procedure was the most acceptable, as it was the least invasive and resulted in no side effects. However, as data have now been accumulating, there is evidence to show that sensory loss also occurs in these patients, albeit often with delayed onset of up to 6 months. Pain relief may also be delayed for some months after the procedure. In those studies using independent outcome measures, it would appear that pain relief periods are similar to those procedures that are performed at the Gasserian ganglion level. Data using a non-validated questionnaire suggest the quality of life is improved.

\section{Microvascular decompression}

This is the only non-destructive procedure, but it is the most invasive operation of all those undertaken for TN. A craniotomy is performed in the postauricular area, which enables the trigeminal nerve to be exposed and vessels to be identified and then moved out of direct contact with the trigeminal nerve. There are again no RCTs and only a handful of studies that have used independent outcome measures. Given that this is a major neurosurgical procedure, it follows that it will be associated with mortality, which varies from $0.2 \%$ to $0.5 \%$. This is considerably lower than when the procedure was first reported some 25 years ago. It has been shown in the USA that highvolume units are likely to have lower mortalities and lower postoperative morbidity. ${ }^{35}$ Most of the complications tend to be in the early postoperative period and include cerebrospinal fluid leaks, haematomas, aseptic meningitis, diplopia and facial weakness. The major long-term complication is ipsilateral hearing loss, which can be as high as $10 \%$.

Table 4 Sources of patient information

\begin{tabular}{|c|c|c|}
\hline \multicolumn{3}{|l|}{ Support groups } \\
\hline \multicolumn{3}{|l|}{ Written information } \\
\hline $\begin{array}{l}\text { J M Zakrzewska. Insight Facts and Stories } \\
\text { behind Trigeminal Neuralgia Gainesville Florida } \\
\text { Trigeminal Neuralgia Association, } 2006^{12} \\
\text { available through any of the support groups, } \\
\text { http://www.Amazon.com/ or Barnes Noble. }\end{array}$ & $\begin{array}{l}\text { Weigel G. Striking Back. Trigeminal Association Gainesville } \\
\text { Florida, } 2000^{37} \text { available through any of the support groups, } \\
\text { http://www.Amazon.com/ or Barnes Noble. }\end{array}$ & $\begin{array}{l}\text { Brain and Spine Foundation, } \\
7 \text { Winchester House, Cranmer Road, } \\
\text { Kennington Park, London SW9 6EJ, UK } \\
+4402077935900 \\
\text { http://www.brainandspine.org.uk/ } \\
\text { Cover a wide range of neurological and } \\
\text { neurosurgical conditions }\end{array}$ \\
\hline
\end{tabular}


Overall, when reporting practice guidelines, the AAN/EFNS could only state that the longest duration of pain relief could be obtained in patients undergoing microvascular decompression, and that there is a lack of direct comparative studies between the different surgical techniques. ${ }^{19} 20$

\section{PATIENT SUPPORT}

Patients with TN have traditionally been managed using a biomedical model, and there are no studies on psychological therapies. Yet in meeting and reading the stories of sufferers, we have become much more aware of the need to provide highquality explanations, to acknowledge the emotions that accompany this disorder, and to provide support. Some of these needs have been addressed by the patients themselves.

As in most areas of medicine, there are now increasing numbers of support groups to help patients gain further information and meet fellow sufferers outside the usual medical environment. As Muir Gray ${ }^{36}$ argues, patients, especially those belonging to support groups, now feel empowered, ask their doctors challenging questions, and expect to be provided with information. As one patient reports, 'As you progress through your disease, you begin to feel alone; you begin to feel angry because somebody did not explain to you what was going to happen to you down the hill'. ${ }^{12}$

There are now several support groups for patients, and details of these are given in table 4.

A review of conferences organised by $\mathrm{TN}$ associations in the USA, UK and Australia show that patients not only attend them in order to gain further knowledge, but also to meet healthcare professionals who have a particular interest in this condition. Satisfaction from these conferences is high. ${ }^{38}$ Narrative from patients with TN has provided rich material in terms of greater appreciation of the severity of the disease and its impact on patients' lives. It has also shown the need for further research, with some of these questions summarised in the current research questions box.

\section{CONCLUSION}

TN is a rare but debilitating condition that can initially be treated in primary care by both medical and dental practitioners, but ultimately care needs to be shared with specialists who can provide a wide range of treatment options. There remain a wide range of research questions that require to be answered.

I would hope that this article has enabled you to become the type of doctor that patients are looking for: "We need to find a medical doctor who is interested in $\mathrm{TN}$ as a specialty, for they have the power to prescribe medications, and to perform procedures and surgeries'. In addition, that you take a partner-

\section{Current research questions}

What is the epidemiology of this condition, its prognosis, risk factors, role of genetics, economic burden?

- What are the diagnostic criteria and variations, and do these affect management?

- What objective tests can be used to validate the clinical diagnosis, including functional MRI?

- How could the cohort multiple randomised controlled trials model provide data on natural history and evaluation of various treatments in more realistic settings ${ }^{39}$ ?

- How can patients be best supported in managing this long-term condition?

\section{Key messages}

- Trigeminal neuralgia is one of the major causes of unilateral episodic shooting pains of the face provoked by light touch activities.

- It is likely that the incidence of trigeminal neuralgia is rising and affecting younger groups.

- Although often managed biomedically, it can result in profound psychological effects.

- Recent international guidelines suggest that the primary drugs remain carbamazepine and oxcarbazepine.

- Surgical treatments, especially the non-destructive technique of microvascular decompression, provide the longest pain-free intervals.

\section{Key references}

- Spatz AL, Zakrzewska JM, Kay EJ. Decision analysis of medical and surgical treatments for trigeminal neuralgia: How patient evaluations of benefits and risks affect the utility of treatment decisions. Pain 2007;131:302-10.

- Gronseth G, Cruccu G, Alksne J, et al. Practice parameter: the diagnostic evaluation and treatment of trigeminal neuralgia (an evidence-based review): report of the Quality Standards Subcommittee of the American Academy of Neurology and the European Federation of Neurological Societies. Neurology 2008;71:1183-90.

- Zakrzewska JM, Linskey ME. Trigeminal neuralgia. Clin Evid (Online) 2009;2009:1207.

- Wiffen P, Collins S, McQuay H, et al. Anticonvulsant drugs for acute and chronic pain. Cochrane Database Syst Rev 2005: CD001133.

- Koopman JS, Dieleman JP, Huygen FJ, et al. Incidence of facial pain in the general population. Pain 2009;147:122-7.

ship role, which is the message that this patient is conveying: 'I managed my own health rather than depend on the advice of any one medical provider. I truly believe that only a team of medical professionals could have effectively helped me, but no such teams exist. Every TN patient must become proactive. They must become the leader of the medical team. They must seek a broad spectrum of input and then they must form their own treatment plan.'

\section{MULTIPLE-CHOICE QUESTIONS (TRUE (T)/FALSE (F); ANSWERS AFTER THE REFERENCES)}

\section{Epidemiology and pathophysiology}

A. Trigeminal neuralgia is more common in women.

B. Trigeminal neuralgia is a form of neuropathic pain.

C. Trigeminal neuralgia is most closely associated with hypertension.

D. The ignition theory for trigeminal neuralgia is supported by clinical evidence.

E. A risk factor is MS.

\section{Classical trigeminal neuralgia includes the following presentation}

A. Memorable onset.

B. Each pain attack lasts between 2 and 3 min 
C. Noxious stimuli trigger pain attacks.

D. Swelling and redness of the skin is noted during an attack.

E. The pain is described as being like an electric shock.

\section{Medical management of trigeminal neuralgia}

A. Gabapentin is the first drug of choice.

B. Oxcarbazepine is better tolerated than carbamazepine but equally effective.

C. Pregabalin has been evaluated in a randomised controlled trial in trigeminal neuralgia patients

D. Lamotrigine can be a useful additional drug in trigeminal neuralgia

E. Opioids are useful in acute treatment of trigeminal neuralgia.

\section{Surgical treatments}

A. Ablative techniques cure trigeminal neuralgia.

$B$. The most invasive procedure is that of microvascular decompression.

C. Balloon micro compression is done at the level of the Gasserian ganglion.

D. Sensory loss is common in ablative procedures.

E. Peripheral techniques are as effective as Gasserian ganglion techniques

\section{Treatment choices}

A. Evaluation of patient support groups have shown them to be worthwhile.

B. Patients marginally prefer to be treated medically.

C. Surgical procedures should be carried out after the first relapse.

D. Published literature on TN, suitable for patients to read. is available.

Acknowledgements We are grateful for the thorough and insightful comments of the reviewers, which have aided the development of this article.

Funding This work was undertaken at UCL/UCLHT who received a proportion of funding from the Department of Health's NIHR Biomedical Research Centre funding scheme.

Competing interests None

Provenance and peer review Commissioned; externally peer reviewed.

\section{REFERENCES}

1. Merskey H, Bogduk N. Classification of Chronic Pain. Descriptors of Chronic Pain Syndromes and Definitions of Pain Terms. 2nd edn. Seattle: IASP Press, 1994

2. Katusic S, Beard CM, Bergstralh $\mathrm{E}$, et al. Incidence and clinical features of trigeminal neuralgia, Rochester, Minnesota, 1945-1984. Ann Neurol 1990;27:89-95.

3. Hall GC, Carroll D, Parry D, et al. Epidemiology and treatment of neuropathic pain: the UK primary care perspective. Pain 2006;122:156-62.

4. Dieleman JP, Kerklaan J, Huygen FJ, et al. Incidence rates and treatment of neuropathic pain conditions in the general population. Pain 2008:137:681-8.

5. McDermott AM, Toelle TR, Rowbotham DJ, et al. The burden of neuropathic pain: results from a cross-sectional survey. Eur J Pain 2006;10:127-35.

6. Tolle $\mathbf{T}$, Dukes $\mathrm{E}$, Sadosky A. Patient burden of trigeminal neuralgia: results from a cross-sectional survey of health state impairment and treatment patterns in six European countries. Pain Pract 2006;6:153-60.

7. Drangsholt $\mathbf{M}$, Truelove E. Trigeminal neuralgia mistaken as temporomandibular disorder. J Evid Base Dent Pract 2001;1:41-50.

8. Koopman JS, Dieleman JP, Huygen FJ, et al. Incidence of facial pain in the general population. Pain 2009:147:122-7.

9. Headache Classification Subcommittee of the International Headache Society. The International Classification of Headache Disorders: 2nd edition. Cephalalgia 2004;24(Suppl 1):9-160

10. Zakrzewska JM. Diagnosis and differential diagnosis of trigeminal neuralgia. Clin J Pain 2002:18:14-21.

11. Limonadi FM, McCartney S, Burchiel KJ. Design of an artificial neural network for diagnosis of facial pain syndromes. Stereotact Funct Neurosurg 2006;84:212-20.

12. Zakrzewska JM. Insights: Facts and Stories Behind Trigeminal Neuralgia. Gainesville: Trigeminal Neuralgia Association, 2006
13. Tyler-Kabara EC, Kassam AB, Horowitz MH, et al. Predictors of outcome in surgically managed patients with typical and atypical trigeminal neuralgia: comparison of results following microvascular decompression. J Neurosurg 2002;96:527-31.

14. Nurmikko TJ, Eldridge PR. Trigeminal neuralgia-pathophysiology, diagnosis and current treatment. Br J Anaesth 2001;87:117-32.

15. Zakrzewska JM, Jassim S, Bulman JS. A prospective, longitudinal study on patients with trigeminal neuralgia who underwent radiofrequency thermocoagulation of the Gasserian ganglion. Pain 1999;79:51-8.

16. Zakrzewska JM, Patsalos PN. Long-term cohort study comparing medical (oxcarbazepine) and surgical management of intractable trigeminal neuralgia. Pain 2002:95:259-66.

17. Devor M, Amir R, Rappaport ZH. Pathophysiology of trigeminal neuralgia: the ignition hypothesis. Clin J Pain 2002;18:4-13.

18. Love S, Coakham HB. Trigeminal neuralgia: pathology and pathogenesis. Brain 2001:124:2347-60.

19. Cruccu G, Gronseth G, Alksne J, et al. AAN-EFNS guidelines on trigeminal neuralgia management. Eur J Neurol 2008;15:1013-28.

20. Gronseth G, Cruccu G, Alksne J, et al. Practice parameter: the diagnostic evaluation and treatment of trigeminal neuralgia (an evidence-based review): report of the Quality Standards Subcommittee of the American Academy of Neurology and the European Federation of Neurological Societies. Neurology 2008;71:1183-90.

21. Wiffen $\mathbf{P}$, Collins $\mathrm{S}, \mathrm{Mc}$ uay $\mathrm{H}$, et al. Anticonvulsant drugs for acute and chronic pain. Cochrane Database Syst Rev 2005;(3):CD001133.

22. Wiffen PJ, McQuay HJ, Moore RA. Carbamazepine for acute and chronic pain. Cochrane Database Syst Rev 2005;(3):CD005451.

23. He L, Wu B, Zhou M. Non-antiepileptic drugs for trigeminal neuralgia. Cochrane Database Syst Rev 2006;(3):CD004029.

24. Wiffen PJ, Rees J. Lamotrigine for acute and chronic pain. Cochrane Database Syst Rev 2007;(2):CD006044

25. Zakrzewska JM, Linskey ME. Trigeminal neuralgia. Clin Evid (Online 2009;2009:1207.

26. Lemos L, Flores S, Oliveira P, et al. Gabapentin supplemented with ropivacain block of trigger points improves pain control and quality of life in trigeminal neuralgia patients when compared with gabapentin alone. Clin J Pain 2008:24:64-75.

27. Obermann $\mathbf{M}$, Yoon MS, Sensen $\mathrm{K}$, et al. Efficacy of pregabalin in the treatment of trigeminal neuralgia. Cephalalgia 2008;28:174-81.

28. Jorns TP, Johnston A, Zakrzewska JM. Pilot study to evaluate the efficacy and tolerability of leviteracetam (keppra) in the treatmetn of patients with trigeminal neuralgia. Eur J Neurol 2009;16:740-4.

29. Rothman KJ, Monson RR. Survival in trigeminal neuralgia. J Chronic Dis 1973;26:303-9.

30. Taylor JC, Brauer S, Espir MLE. Long-term treatment of trigeminal neuralgia. Postgrad Med J 1981;57:16-18.

31. Spatz AL, Zakrzewska JM, Kay EJ. Decision analysis of medical and surgical treatments for trigeminal neuralgia: how patient evaluations of benefits and risks affect the utility of treatment decisions. Pain 2007;131:302-10.

32. Bittar GT, Graff-Radford SB. The effects of streptomycin/lidocaine block on trigeminal neuralgia: a double blind crossover placebo controlled study. Headache 1993:33:155-60.

33. Stajcic Z, Juniper RP, Todorovic L. Peripheral streptomycin/lidocaine injections versus lidocaine alone in the treatment of idiopathic trigeminal neuralgia. A double blind controlled trial. J Craniomaxillofac Surg 1990:18:243-6.

34. Erdine S, Ozyalcin NS, Cimen A, et al. Comparison of pulsed radiofrequency with conventional radiofrequency in the treatment of idiopathic trigeminal neuralgia. Eur $J$ Pain 2007:11:309-13.

35. Kalkanis SN, Eskandar EN, Carter BS, et al. Microvascular decompression surgery in the United States, 1996 to 2000: mortality rates, morbidity rates, and the effects of hospital and surgeon volumes. Neurosurgery 2003;52:1251-61.

36. Muir Gray JA. The Resourceful Patient. Oxford: eRosetta Press, 2002.

37. Weigel G, Casey KF. Striking Back. The Trigeminal Neuralgia Handbook. Barnegat Light: The Trigeminal Neuralgia Association, 2000.

38. Zakrzewska JM, Jorns TP, Spatz A. Patient led conferences-who attends, are thei expectations met and do they vary in three different countries? Eur J Pain 2009;13:486-91.

39. Relton C, Torgerson D, O'Cathain A, et al. Rethinking pragmatic randomised controlled trials: introducing the "cohort multiple randomised controlled trial" design. BMJ 2010;340:c1066.

\section{ANSWERS}

1. $A(T): B(T): C(F) ; D(T) ; E(T)$

2. $A(T) ; B(F) ; C(F) ; D(F) ; E(T)$

3. $A(F) ; B(T) ; C(F) ; D(T) ; E(F)$

4. $A(F) ; B(T) ; C(T) ; D(T) ; E(F)$

5. $A(T) ; B(F) ; C(F) ; D(T)$ 